Article

\title{
Analysis of Magnetic Properties of Nano-Particles Due to a Magnetic Dipole in Micropolar Fluid Flow over a Stretching Sheet
}

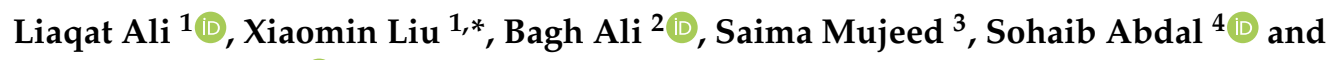 \\ Shahid Ali Khan ${ }^{2}$ (1) \\ 1 School of Energy and Power, Xi'an Jiaotong University, No. 28, Xianning West Road, Xi'an 710049, China; \\ math1234@stu.xjtu.edu.cn \\ 2 Department of Applied Mathematics, Northwestern Polytechnical University, Dongxiang Road, \\ Beilin District, Xi'an 710129, China; baghalisewag@mail.nwpu.edu.cn (B.A.); \\ shahidalimaths@mail.nwpu.edu.cn (S.A.K.) \\ 3 School of Management, Xi'an Jiaotong University, No. 28, Xianning West Road, Xi'an 710049, China; \\ majeed@stu.xjtu.edu.cn \\ 4 School of Mathematics, Northwest University, No. 229 North Taibai Avenue, Xi'an 710069, China; \\ sohaib@stumail.nwu.edu.cn \\ * Correspondence: liuxm@xjtu.edu.cn
}

Received: 23 December 2019; Accepted: 9 February 2020; Published: 13 February 2020

\begin{abstract}
This article explores the impact of a magnetic dipole on the heat transfer phenomena of different nano-particles $\mathrm{Fe}$ (ferromagnetic) and $\mathrm{Fe}_{3} \mathrm{O}_{4}$ (Ferrimagnetic) dispersed in a base fluid (60\% water $+40 \%$ ethylene glycol) on micro-polar fluid flow over a stretching sheet. A magnetic dipole in the presence of the ferrities of nano-particles plays an important role in controlling the thermal and momentum boundary layers. The use of magnetic nano-particles is to control the flow and heat transfer process through an external magnetic field. The governing system of partial differential equations is transformed into a system of coupled nonlinear ordinary differential equations by using appropriate similarity variables, and the transformed equations are then solved numerically by using a variational finite element method. The impact of different physical parameters on the velocity, the temperature, the Nusselt number, and the skin friction coefficient is shown. The velocity profile decreases in the order $\mathrm{Fe}$ (ferromagnetic fluid) and $\mathrm{Fe}_{3} \mathrm{O}_{4}$ (ferrimagnetic fluid). Furthermore, it was observed that the Nusselt number is decreasing with the increasing values of boundary parameter $(\delta)$, while there is controversy with respect to the increasing values of radiation parameter $(N)$. Additionally, it was observed that the ferromagnetic case gained maximum thermal conductivity, as compared to ferrimagnetic case. In the end, the convergence of the finite element solution was observed; the calculations were found by reducing the mesh size.
\end{abstract}

Keywords: nano-particles; magnetic dipole; finite element method (FEM); viscous dissipation; micro-polar

\section{Introduction}

The study of magnetic nano-particles plays an important role due to its inclusive use at many industrial applications and in several other flow phenomena. The enhancement of heat transferring in the two-phase fluid flow has been studied for many years. The fluids are often utilized in the heat transferring phenomena as a heat transporter. Therefore, over the last few decades, nano-fluids have been the subject of great attention for researchers. Nano-fluids have industrialized by the diffusion of nano-meter-scaled dense elements into fluids, which contain different materials (metal oxides, 
metals, etc.). Such attention is the due to their credible applications in heat transfer, innovative magnetic constituents, and microelectronic freezing. Magnetic nano-fluids create a different kind of nano-fluid that shows both fluidic and magnetic properties. These fluids interest researchers and scientists because they have several applications in the field of bio-medicine, chemical engineering, micro-electro-mechanical, compounds, colored stains, the refinement of melted metals, shock absorbers, pumps, etc. [1-4]. The transfer of heat is the elementary feature of the vast utilization via applications, which are subjected to the thermal conductivity of operational liquids, and include procedures with the capability of thermal utilization and erection. There are many periodicals on nano-fluids that seek to recognize their behavior so that it can be utilized wherever the transfer of heat enhancement is overriding, such as in several manufacturing appliances such as transportation, nuclear-powered reactors, and electronics and in bio-medicine and nutrition. Nano-fluid has been found wherever the heat transfer might be reduced or enhanced. Wen [5] represents the insufficient caring of the structure and mechanism of nano-fluids and their applications.

The suspension of particles is instigated by Brownian motion. Under normal conditions, the particles will not settle down. The magnetism of nano-scaled ferromagnetic particles has been truncated during surfactant van der Waals forces of appropriate strength to obstruct the magnetic forces. When the magnetizable supplies are rare to peripheral magnetizing field $\mathrm{H}$, magnetic dipoles in the material will align and generate a magnetization M. Initially, Sakiadis [6] and Crane [7] explored the nano-fluid flow and the stretching sheet. Mee [8] showed that ferrofluids can be used to detain magnetic dominion structures on the surface of ferrofluids in the presence of a magnetic dipole. Neuringer [9] described the flow of ferrofluids under the influence of a magnetic field and thermal gradients. Nadeem et al. [10] illustrated the impact of a magnetic dipole through a porous medium in the flow of ferrofluid. Anderson et al. [11] investigated the stimulus of the magnetic field generated by a magnetic dipole through a stretched sheet, and the magnetic field was responsible for decreasing the motion of a fluid. Recently, Bognar et al. [12] investigated the magneto thermo-mechanical association concerning the heated viscid incompressible ferrofluid and the cold wall in the presence of a variable magnetic field. Tang and Fu [13] examined a natural macromolecule-based coating with adjoined magnetic $\mathrm{Fe}_{3} \mathrm{O}_{4}$ nano-particles that were formulated for wood surface modification. Liaqat et al. [14] investigated the impact of multi-slip and solutal boundary conditions on magneto-hydrodynamic (MHD), unsteady, bio-convective, micropolar nano-fluid, restraining gyrotactic microorganism heat and mass transfer effect over a stretching/shrinking sheet. Mabood et al. [15] showed that there is a direct relation of the magnetic parameter with Nusselt and Sherwood numbers. Magnetic nano-fluids (that contain colloidal mixtures of super-paramagnetic nano-particles suspended in a nonmagnetic carrier fluid) generate a special kind of nano-fluid that shows both magnetic and fluid properties. These fluids fascinate scientists and researchers because they have many applications, particularly in the field of colored pigments, chemical engineering, biomedicine, micro-electromechanical systems, catalysts, leak-proof seals, the purification of molten metals, coolers of nuclear reactors, shock absorbers, micro-fluidic valves and pumps, and lithographic patterning [16-18].

Turkyilmazoglu [19] analyzed the heat transfer and the micro-polar fluid flow through a stretching sheet. Pradhan et al. [20] carried out an analysis of the free convective fluid flow over an electrically conducted micro-polar fluid through a penetrable stretching sheet in the presence of the porous medium. Ishak et al. [21] studied stagnation point flow through a shrinking sheet in a micro-polar fluid. Eringen [22] established a philosophy of micro-polar fluid that cannot be explicated by classical Navier-Stokes equations due to micro inertia and gyration or micro-gyration impacts. Gorla [23] represented a study on micro-polar boundary layer flow at the stagnation point on the moving wall. Li et al. [24] analyzed the impacts of element volume fraction, surfactants, and the magnetic field on the transporting properties of water-based Fe magnetic nano-fluid. Yirga and Tesfay [25] conducted a heat and mass transfer investigation of nano-fluid over a penetrable stretching sheet. The authors disclosed that Ag water nano-fluid has greater skin friction as compared to $\mathrm{Cu}$ water nano-fluid. Further applications that are appropriate to the flow of liquors are suggested in [26,27]. Ibrahim 
and Shankar [28] revealed the heat transfer and the magneto-hydrodynamic boundary layer flow of nano-fluids through a penetrable stretching sheet with velocity, thermal, and solutal-slip boundary conditions. Das [29] investigated an imperative numerical analysis on the convective heat transfer narration of nano-fluids through a penetrable stretching sheet in the presence of partial slip, thermal buoyancy, and internal heat development/captivation. Abbas et al. [30] investigated the influences of radioactivity in the presence of a similar magnetic field for nano-fluids on a frizzy stretching sheet by integrating the implications of slip. The reimbursement of the accumulation of ferrimagnetic and ferromagnetic nano-particles increases the transfer of mass and dominates the consistency of the nano-fluid. Numerous nano-fluid imitations have been generated on the basis of different types of nano-particles and the reversing gesticulation scheme of fluid.

The literature lacks investigations on the impact of viscous dissipation and the different kinds of magnetic nano-particles $\mathrm{Fe}$ (ferromagnetic) and $\mathrm{Fe}_{3} \mathrm{O}_{4}$ (ferrimagnetic) on micro-polar fluid flow, heat transfer over the stretching sheets. $\mathrm{H}_{2} \mathrm{O}$ (water) and $\mathrm{C}_{2} \mathrm{H}_{6} \mathrm{O}_{2}$ (Ethylene glycol) are used as base fluids in the presence of a magnetic dipole. The foremost intention of the current study was to investigate the behavior of different magnetic nano-particles and thermal conductivity. The behavior of the existing parameters is demonstrated graphically. Moreover, the graphical representation of the Nusselt number and the concentration of magnetic ferrites is discussed. We numerically inspected the behavior of skin friction and also, describe the influence of various parameters of the flow. Subsequently, a numeral assessment of current results is represented and discussed using diagrams.

\section{Problem Description}

Considering a two-dimensional MHD, incompressible, boundary layer, micro-polar magnetic nano-fluid flow over an electrically nonconducted stretching surface, we found that the magnetic nano-fluid contains ferromagnetic and ferrimagnetic particles suspended with ethylene glycol $\mathrm{C}_{2} \mathrm{H}_{6} \mathrm{O}_{2}$ as a conventional fluid over a stretching surface. We decided on a two-coordinate system so that the dimensions of the surface would be designated along the x-axis and the y-axis. $U_{w}$ is the velocity of the sheet, as shown in Figure 1. The stretching gives the impression in the sheet and is proportionate to the distance from the origin. Moreover, the magnetic dipole is located nearly at distance $b$ from the $x$-axis outside the fluid and is retained in such a manner that its middle is accurately placed on the $y$-axis. The magnetic field points of the magnetic dipole are applied in the positive $x$-direction. By saturating the ferrofluid, the magnetic dipole substantially escalates the strength of the magnetic field. The temperature $T_{w}$ at the stretching sheet is lower than the cure temperature $T_{\mathcal{c}}$, and $T=T_{\infty}$ is the temperature of the fluid away from the surface, where $T_{c}>T_{\infty}>T_{w}$ and the fluid that is away from $T_{c}$ are incapable of being magnetized. The variable temperature $T_{w}=T_{0}+d_{1} x$ is considered at the surface and is $T_{\infty}=T_{0}+d_{2} x$, away from the surface. The governing equations for flow can be expressed as [31]

$$
\begin{gathered}
\frac{\partial u}{\partial x}+\frac{\partial v}{\partial y}=0 \\
u \frac{\partial u}{\partial x}+v \frac{\partial u}{\partial y}=-\frac{1}{\rho} \frac{\partial p}{\partial x}+\frac{\mu_{0}}{\rho} M \frac{\partial H}{\partial x}+\left(\frac{\mu_{n f}+\kappa}{\rho_{n f}}\right) \frac{\partial^{2} u}{\partial y^{2}}+\frac{\kappa}{\rho_{n f}} \frac{\partial w}{\partial y} \\
u \frac{\partial w}{\partial x}+v \frac{\partial w}{\partial y}=\frac{\gamma_{n f}}{\left(\rho_{n f}\right) j} \frac{\partial^{2} w}{\partial y^{2}}-\frac{\kappa}{\left(\rho_{n f}\right) j}\left(2 w+\frac{\partial u}{\partial y}\right) \\
u \frac{\partial T}{\partial x}+v \frac{\partial T}{\partial y}+\left(u \frac{\partial H}{\partial x}+v \frac{\partial H}{\partial y}\right) \frac{\mu_{0}}{\left(\rho_{c p}\right)_{n f}} T \frac{\partial M}{\partial T}=\alpha_{n f} \frac{\partial^{2} T}{\partial y^{2}}-\frac{\partial q_{r}}{\partial y}+\frac{\mu_{n f}}{\left(\rho_{c p}\right)_{n f}}\left[\left(\frac{\partial u}{\partial y}\right)^{2}+2\left(\frac{\partial v}{\partial y}\right)^{2}\right]
\end{gathered}
$$




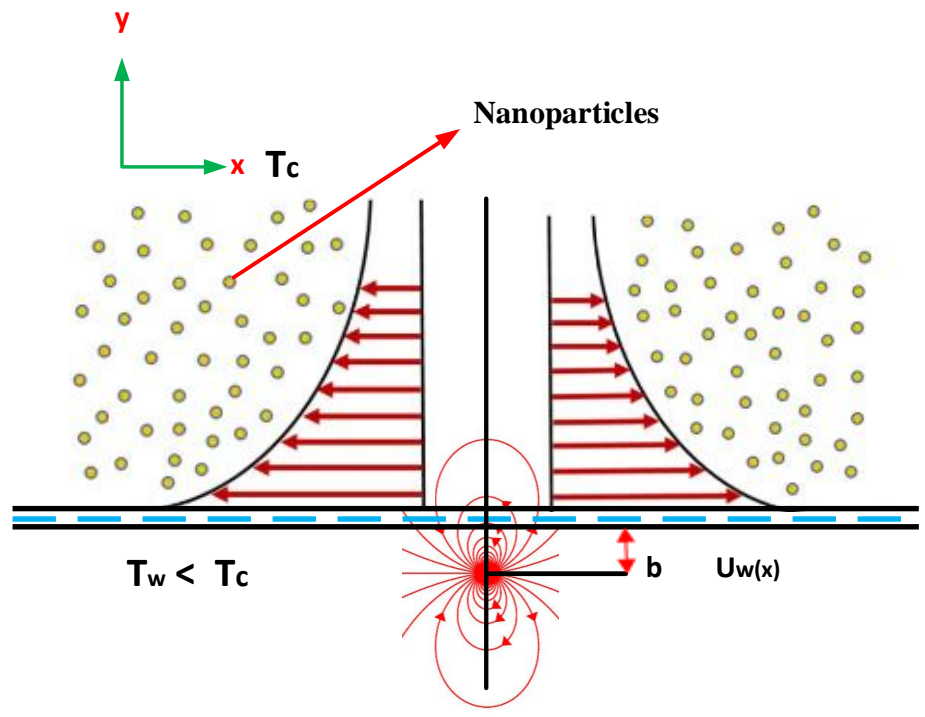

Figure 1. Configuration of the flow model.

The velocity components along the $\mathrm{x}$-axis and y-axis are $(u, v)$, respectively. $\alpha_{n f}$ is the normal anxiety moduli, $\rho_{n f}$ is the fluid density, $\mu_{n f}$ is the dynamic viscosity of the fluid, $p$ is the pressure, $M$ is the magnetization, $H$ is the magnetic field, $\mu_{0}$ is the magnetic penetrability, and $\left(\rho_{c p}\right)_{n f}$ is the thermal capability of the nano-fluid. The spin gradient viscosity is $\gamma_{n f}$ and is expressed as $\gamma=\sqrt{S \rho b^{2}} / \sqrt{\mu}$, where $b$ is constant, and $q_{r}$ is the heat flux that is expressed as $q_{r}=-\frac{4 \sigma^{*}}{3 \kappa^{*}} \frac{\partial T^{4}}{\partial y}$, where $\sigma^{*}$ is the Stefan-Boltzmann number, and $\kappa^{*}$ represents the mean assimilation coefficients. The thermos-physical factors are [32]

$$
\begin{aligned}
& A_{1}=\rho_{n f}=(1-\phi)_{\rho f}+\phi \rho_{s}, \quad A_{2}=\mu_{n f}=\mu_{f} /(1-\phi)^{2.5} \\
& A_{3}=\left(\rho C_{p}\right)_{n f}=(1-\phi)\left(\rho C_{p}\right)_{f}+\phi\left(\rho C_{p}\right)_{s}, \quad A_{4}=\frac{\kappa_{n f}}{\kappa_{f}}=\frac{\left(\kappa_{s}+2 \kappa_{f}\right)-2 \phi\left(\kappa_{f}-\kappa_{s}\right)}{\left(\kappa_{s}+2 \kappa_{f}\right)+\phi\left(\kappa_{f}-\kappa_{s}\right)}
\end{aligned}
$$

Boundary conditions for the above mathematical model are given as

$$
\begin{gathered}
u=U_{w}(x)=S x, \quad v=-v_{0}, \quad T=T_{w}, \quad w=-m \frac{\partial u}{\partial y}, \quad \text { as } y=0 \\
U_{e}(x)=Q x, \quad w=0, \quad T \rightarrow T_{\infty}, \quad \text { as } \quad y \rightarrow \infty
\end{gathered}
$$

$T_{0}, d_{1}$, and $d_{2}$ are allusion temperature and dimensionless quantities, respectively. The temperature at the surface is $T_{w}$, the Curie temperature is $T_{\mathcal{c}}$, and $T_{\infty}$ is the temperature of the fluid away from the surface. $S$ and $Q$ are constants.

The magnetic nano-fluid flow is affected via the dipole field by means of magnetic scalar potential $\tau$ [11]:

$$
\tau=\left(\frac{\gamma^{*}}{2 \pi}\right) x /\left(x^{2}+(y+b)^{2}\right)
$$

At the source position, $\gamma^{*}$ denotes the strength of magnetic field, $b$ represents the distance from the $\mathrm{x}$-axis to the center of magnetic field, and the $x, y$ components of the magnetic field $H$ are

$$
\begin{gathered}
H_{x}=-\partial \tau / \partial x=\left(\frac{\gamma^{*}}{2 \pi}\right)\left(x^{2}-(y+b)^{2}\right) /\left(x^{2}+(y+b)^{2}\right)^{2} \\
H_{y}=-\partial \tau / \partial y=\left(\frac{\gamma^{*}}{2 \pi}\right)(2 x(y+c)) /\left(x^{2}+(y+c)^{2}\right)^{2}
\end{gathered}
$$


The body force is proportionate to the gradient of magnitude $H$, which is

$$
H=\sqrt{(\partial \tau / \partial x)^{2}+(\partial \tau / \partial y)^{2}}
$$

By using Equations (7) and (8) to solve Equation (9) by expanding the power of $x$ up to $x^{2}$, then we obtain

$$
\begin{gathered}
\partial H / \partial x=-\frac{\gamma^{*}}{2 \pi}\left(2 x /(y+b)^{4}\right) \\
\partial H / \partial y=\frac{\gamma^{*}}{2 \pi}\left(-2 /(y+b)^{3}+4 x^{2} /(y+b)^{5}\right)
\end{gathered}
$$

The impact of the variation of magnetization $M$ with temperature $T$ can be expressed as linear equation $M=K_{1}(T-T \infty)$, where $K_{1}$ is a pyromagnetic coefficient. Let us now introduce non-dimensional variables to solve the system of Equations (1)-(4). We substitute the similarity transformations as follows [11]:

$$
\psi(\zeta, \eta)=(\mu / \rho) \zeta f(\eta), \theta(\zeta, \eta)=\left(T_{\infty}-T\right) /\left(T_{0}-T_{w}\right)=\theta_{1}(\eta)+\zeta^{2} \theta_{2}(\eta)
$$

where $\mu$ is the dynamic viscosity, $\theta_{1}(\eta)$ and $\theta_{2}(\eta)$ are the dimensionless temperature resp, and the non-dimensional co-ordinates are

$$
\eta=y \sqrt{\left(S \rho_{f}\right) / \mu_{f}}, \quad \zeta=x \sqrt{\left(S \rho_{f}\right) / \mu_{f}}
$$

The components of the velocity for the stream function $\psi(\zeta, \eta)$ and for temperature $\theta(\zeta, \eta)$ are

$$
u=\frac{\partial \psi}{\partial y}=S x f^{\prime}(\eta), \quad v=-\frac{\partial \psi}{\partial x}=-\sqrt{\left(S v_{f}\right)} f(\eta)
$$

According to similarity transformations, Equations (12)-(14), the system of Equations (1)-(4) are converted into a system of ordinary differential equations (ODEs):

$$
\begin{gathered}
\left(A_{5}+K\right) \frac{d^{3} f}{d \eta^{3}}-A_{1}\left(\frac{d f}{d \eta}\right)^{2}+A_{1} f \frac{d^{2} f}{d \eta^{2}}+K \frac{d g}{d \eta}-\frac{2 \beta \theta_{1}}{(\eta+\gamma)^{4}}+A_{1} R^{2}=0 \\
\left(A_{5}+\frac{K}{2}\right) \frac{d^{2} g}{d \eta^{2}}-A_{1} f \frac{d g}{d \eta}+A_{1} g \frac{d f}{d \eta}-K\left(2 g+\frac{d^{2} f}{d \eta^{2}}\right)=0 \\
A_{4}(1+N) \frac{d^{2} \theta_{1}}{d \eta^{2}}+A_{3}\left(f \frac{d \theta_{1}}{d \eta}-2 \theta_{1} \frac{d f}{d \eta}\right)+\frac{2 \lambda \beta f\left(\theta_{1}-\epsilon\right)}{(\eta+\gamma)^{3}}-2 \lambda A_{5}\left(\frac{d f}{d \eta}\right)^{2}=0 \\
A_{4}(1+N) \frac{d^{2} \theta_{2}}{d \eta^{2}}+A_{3}\left(f \frac{d \theta_{2}}{d \eta}-4 \theta_{2} \frac{d f}{d \eta}\right)+\frac{2 \lambda \beta \theta_{2}}{(\eta+\gamma)^{3}} \\
-\lambda \beta\left(\theta_{1}-\epsilon\right)\left[2 \frac{d f}{d \eta} /(\eta+\gamma)^{4}+4 f /(\eta+\gamma)^{5}\right]-\lambda A_{5}\left(\frac{d^{2} f}{d \eta^{2}}\right)^{2}=0
\end{gathered}
$$

For the above problem, the transformed boundary conditions are

$$
\begin{gathered}
f(0)=f_{0}, \quad \frac{d f(0)}{d \eta}=1, \quad g(0)=-\delta \frac{d^{2} f(0)}{d \eta^{2}}, \quad \theta_{1}=1, \quad \text { and } \quad \theta_{2}=0 . \\
\frac{d f(\infty)}{d \eta} \rightarrow R, \quad g \rightarrow 0, \quad \theta_{1}(\infty) \rightarrow 0, \quad \text { and } \quad \theta_{2}(\infty) \rightarrow 0
\end{gathered}
$$

where $A_{5}=(1-\phi)^{-2.5}$, and the primes show the differentiation with respect to $\eta$. Parameters in Equations (15)-(18) are explained by the following: 


$$
\begin{array}{ll}
R=Q / S, \quad P_{r}=v / \alpha, \quad \delta m=S b / \rho \nu, \quad \epsilon=T_{\infty} / T_{0}-T_{w}, \quad \beta=\frac{\gamma^{\prime}}{2 \pi} \frac{K \mu_{0}\left(T_{0}-T_{w}\right) \rho}{\mu_{0}^{2}} \\
\lambda=S \mu^{2} / \rho \kappa\left(T_{0}-T_{w}\right), \quad \gamma^{\prime}=\sqrt{S \rho b^{2}} / \sqrt{\mu}, \quad N=\left(16 \sigma^{*} T_{\infty}^{3}\right) /\left(3 \kappa^{*} K\right)
\end{array}
$$

Here, $\beta$ is the ferromagnetic parameter, $\lambda$ is the viscous dissipation, $K$ is the micro-rotation parameter, $b$ is the distance from the origin to the magnetic dipole, $\delta$ is the boundary parameter, and $T_{\mathcal{C}}$ is the Curie temperature. $\delta m$ is the elasticity parameter, $\mathrm{N}$ is the thermal radiation parameter, $R$ is the ratio of $Q$ and $S$, and $\operatorname{Pr}$ is the Prandtl number. The thermophysical properties of the base fluid (60\% water $+40 \%$ ethylene glycol) and the two different magnetic nano-particles are displayed in Table 1 . The most substantial corporeal measurements are the skin friction coefficient and the Nusselt number, and the explanation of these dimensionless corporal measurements is given as

$$
C_{f x}=-2 \tau_{w} / \rho_{n f} U_{w}^{2}, \quad \tau_{w}=\mu_{n f}(\partial u / \partial y)_{y=0^{\prime}} \quad N_{u x}=-\frac{K_{n f}}{K_{f}}(1+N) \frac{x}{\left(T_{0}-T_{w}\right)}[\partial T / \partial y]_{y=0}
$$

When Equations (13) and (14) are substituted in Equation (21), the resulting form is

$$
\begin{gathered}
C_{f}\left(R e_{x}\right)^{-1 / 2}=-(A 5+(1-\delta) K) \frac{d^{2} f(0)}{d \eta^{2}} \\
N_{u}\left(R e_{x}\right)^{-1 / 2}=A_{4}(1+N)\left[\frac{d \theta_{1}(0)}{d \eta}+\eta^{2} \frac{d \theta_{2}(0)}{d \eta}\right]
\end{gathered}
$$

where the local Reynolds number is $R e_{x}=\frac{x u_{w}(x)}{v_{f}}$.

Table 1. Physical properties of the base fluid (60\% water $+40 \%$ ethylene glycol) and nano-particles.

\begin{tabular}{cccc}
\hline Properties & Base Fluid [33] & Ferromagnetic (Fe) [34] & Ferrimagnetic $\left(\mathbf{F e}_{3} \mathbf{O}_{4}\right)$ [34] \\
\hline$C_{p}\left(J \cdot\left(k g \cdot(K)^{-1}\right)\right.$ & 3752 & 447 & 670 \\
$\rho\left(\mathrm{kg} \cdot\left(\mathrm{m}^{-3}\right)\right)$ & 1054 & 7870 & 5180 \\
$\kappa\left(W \cdot\left(\mathrm{m} \cdot(\mathrm{K})^{-1}\right)\right.$ & 0.416 & 80.2 & 9.7 \\
\hline
\end{tabular}

\section{Implementation of the Method}

The finite element method was implemented to obtained the numerical solution of the coupled nonlinear system of differential equations that are detailed in Equations (15)-(18) with the boundary conditions expressed in Equations (19) and (20). The finite element method is most capable and reliable compared to many other numerical methods, such as Admoian decomposition method (ADM), homotopy perturbation method (HPM), and finite difference method (FDM). The inclusive features of the finite element method have been described by Reddy [35], who also used the finite element method (FEM) with commercial software such as MATLAB, ANSYS, ADINA, and ABAQUS. Swapna et al. and Rana et al. [36,37] showed that the variational finite element method solves the boundary value problem effectively, quickly, and accurately. To use the finite element method (FEM) and solve the system of differential equations, Equations (15)-(18), firstly we have to consider the following:

$$
\frac{d f}{d \eta}=h
$$

Equations (15)-(18) take the form

$$
\left(A_{5}+K\right) \frac{d^{2} h}{d \eta^{2}}+A_{1} f \frac{d h}{d \eta}-A_{1} h^{2}+K \frac{d g}{d \eta}-\frac{2 \beta \theta_{1}}{(\eta+\gamma)^{4}}+A_{1} R^{2}=0
$$




$$
\begin{gathered}
\left(A_{5}+\frac{K}{2}\right) \frac{d^{2} g}{d \eta^{2}}-A_{1} f \frac{d g}{d \eta}+A_{1} g h-K\left(2 g+\frac{d h}{d \eta}\right)=0 \\
A_{4}(1+N) \frac{d^{2} \theta_{1}}{d \eta^{2}}+A_{3}\left(f \frac{d \theta_{1}}{d \eta}-2 \theta_{1} h\right)+\frac{2 \lambda \beta f\left(\theta_{1}-\epsilon\right)}{(\eta+\gamma)^{3}}-2 \lambda A_{5} h^{2}=0 \\
A_{4}(1+N) \frac{d^{2} \theta_{2}}{d \eta^{2}}+A_{3}\left(f \frac{d \theta_{2}}{d \eta}-4 \theta_{2} h\right)+\frac{2 \lambda \beta \theta_{2}}{(\eta+\gamma)^{3}} \\
-\lambda \beta\left(\theta_{1}-\epsilon\right)\left[2 h /(\eta+\gamma)^{4}+4 f /(\eta+\gamma)^{5}\right]-\lambda A_{5}\left(\frac{d h}{d \eta}\right)^{2}=0
\end{gathered}
$$

The correspondent boundary conditions are reduced to subsequential form:

$$
\begin{gathered}
f(0)=f_{0}, \quad h(0)=1, \quad g(0)=-\delta \frac{d^{2} f(0)}{d \eta^{2}}, \quad \theta_{1}=1, \quad \text { and } \theta_{2}=0 \\
h(\infty) \rightarrow R, \quad g \rightarrow 0, \quad \theta_{1}(\infty) \rightarrow 0, \quad \text { and } \quad \theta_{2}(\infty) \rightarrow 0
\end{gathered}
$$

The given domain is divided into a finite number of subintervals known as finite elements. The assembly of finite elements is designated as the finite element mesh, and the physical boundary conditions are executed on the accumulated equations. From the mesh, a typical element is separated, and the variational formulation of the given problem over that element is constructed. The estimated solution of the variational problem is assumed. On substituting it into the variational form, the element equations are formed. The element matrix is constructed by using the element interpolation functions. The appropriate variational formulation details are given in Appendix A.

Subsequently, the accumulation of element equations, a substantial system of nonlinear equations, is achieved. Moreover, an iterative structure is needed to resolve the system of nonlinear equations for an efficient solution. At the inferior level of iterations, the functions $\bar{f}, \bar{h}, \bar{g}, \bar{\theta}_{1}$, and $\bar{\theta}_{2}$ are assumed to be known to linearize the framework and are required until an accuracy of 0.00005 is not obtained. To ensure mesh independence, a mesh affectability practice was performed. Table 2 shows the convergence of the results. The number of elements increased as follows: $n=40,100,160,240,340$, 400,480 , and 500. Based on Table 2, there is no significant difference that can be seen in the values of functions $\bar{h}, \bar{g}, \bar{\theta}_{1}$, and $\bar{\theta}_{2}$ as number of elements increases beyond $\mathrm{n}=480$; thus, the last results are stated for $\mathrm{n}=480$ elements.

Table 2. FEM convergence results of $h(\eta), g(\eta), \theta_{1}(\eta)$, and $\theta_{2}(\eta)$ for different numbers of elements when $\operatorname{Pr}=2, K=0.1, \lambda=0.01, \phi=0, \beta=0.5, \epsilon=2, \delta=0.5, f_{0}=0.2$, and $N=0.5$.

\begin{tabular}{ccccc}
\hline Number of Elements & $\boldsymbol{h ( 1 . 5 )}$ & $\boldsymbol{g ( \mathbf { 1 . 5 } )}$ & $\boldsymbol{\theta}_{\mathbf{1}}(\mathbf{1 . 5})$ & $\boldsymbol{\theta}_{\mathbf{2}}(\mathbf{1 . 5})$ \\
\hline 40 & 0.191650 & 0.121507 & 0.087617 & 0.000102 \\
100 & 0.192679 & 0.121595 & 0.089334 & 0.000101 \\
160 & 0.192796 & 0.121602 & 0.089529 & 0.000101 \\
240 & 0.192837 & 0.121604 & 0.089598 & 0.000101 \\
340 & 0.192853 & 0.121605 & 0.089626 & 0.000101 \\
400 & 0.192859 & 0.121606 & 0.089634 & 0.000100 \\
480 & 0.192862 & 0.121606 & 0.089639 & 0.000100 \\
500 & 0.192863 & 0.121606 & 0.089641 & 0.000100 \\
\hline
\end{tabular}

\section{Results and Discussion}

The features of miscellaneous parameters in the flow field have been shown. The impacts of different ferromagnetic and ferrimagnetic nano-particles on the flow velocity, temperature, Nusselt number, and skin friction were investigated with varying physical parameters, including $\beta, \lambda, \epsilon, q r$, $\delta, K$, and $P r$, i.e., the ferromagnetic parameter, viscous dissipation, Curie temperature, radiation, the boundary parameter, the micro-rotational parameter, and the Prandtl number, and $R$ (ratio) are investigated. 
Furthermore, all the other parameters were fixed $(P r=2, k=0.1, \lambda=0.01, \beta=0.5, E=2$, $\delta=0.5, f_{0}=0.2, N r=0.3$, and $R=0.5$ ). Our results have decent agreement with the published results that declare the legitimacy of the finite element method and is shown in Tables 3 and 4. Table 3 shows the consequences of the heat transfer proportion, which is assimilated through the finite element method and is associated through the results of earlier studies and with the exact solutions of [38-41]. To ensure the accuracy of the existing precise values, the conclusions attained by the finite element method for the Nusselt number, the steady flow and the computed results that are stated in earlier studies are shown in Table 3. The current results achieved the same intensity and are accurate. To determine the uniformity and validation of the results, the results were exhaustively compared with those of [42-44], and these results were effectively replicated, as shown in Table 4 . The current results are in complete concurrence. The grid invariance test was performed to ensure accuracy to five decimal digits. Figure 2 shows the effects of the ferromagnetic and ferrimagnetic particles and the suction/injection parameter $f_{0}$ on the velocity profile $f^{\prime}(\eta)$ for both the linear and nonlinear sheet. The velocity profile is decreasing and the momentum boundary layer thickness increases as values of $f_{0}$ increase up to a certain distance $\eta$. The flow velocity form intensifies due to ferromagnetic ( $\mathrm{Fe}$ ) and ferrimagnetic $\left(\mathrm{Fe}_{3} \mathrm{O}_{4}\right)$. This shows that the thickness of the boundary layer for nano-particle $\mathrm{Fe}_{3} \mathrm{O}_{4}$ is more progressive than that of Fe. Compatibly, Figure 3 illustrates that micro-rotation velocity fluctuates directly by inoculation through the stretching sheet and that the velocity field decreases with increasing values of $f_{0}$ up to a certain distance $\eta$. Figure 4 shows that the thickness of the thermal boundary layer of ferromagnetic ( $\mathrm{Fe})$ nano-particles is maximally intensified than ferrimagnetic $\left(\mathrm{Fe}_{3} \mathrm{O}_{4}\right)$.

Table 3. Comparison of the Nusselt number $\left(-\theta^{\prime}(0)\right)$ for different values of $P r$, when all others parameters are zero.

\begin{tabular}{cccccc}
\hline Pr & $\begin{array}{c}\text { Liaqat et al. } \\
{[38]}\end{array}$ & $\begin{array}{c}\text { Bagh et al. } \\
{[\text { [39] }}\end{array}$ & $\begin{array}{c}\text { Majeed et al. } \\
{[40]}\end{array}$ & $\begin{array}{c}\text { Bachok et al. } \\
{[41]}\end{array}$ & $\begin{array}{c}\text { FEM } \\
\text { (Current Results) }\end{array}$ \\
\hline 0.72 & 0.808634 & 0.808634 & 0.808640 & 0.8086 & 0.808634 \\
1.00 & 1.000001 & 1.000001 & 1.000000 & 1.0000 & 1.000008 \\
3.00 & 1.923678 & 1.923683 & 1.923609 & 1.9237 & 1.923678 \\
10.0 & 3.720668 & 3.720674 & 3.720580 & 3.7207 & 3.720668 \\
\hline
\end{tabular}

Table 4. Comparison of skin friction for different values of micro-rotation parameter $K$ and boundary parameter $\delta$, when all others parameters are zero.

\begin{tabular}{cccccc}
\hline $\mathbf{K}$ & $\delta$ & $\begin{array}{c}\text { Qasim et al. } \\
{[42]}\end{array}$ & $\begin{array}{c}\text { Abid Hussanan et al. } \\
{[43]}\end{array}$ & $\begin{array}{c}\text { Kumar } \\
{[44]}\end{array}$ & $\begin{array}{c}\text { FEM } \\
\text { (Current Results) }\end{array}$ \\
\hline 0.0 & 0.5 & -1.000000 & -1.0000000 & - & -1.0000089 \\
1.0 & - & -1.224741 & -1.2247448 & - & -1.2248199 \\
2.0 & - & -1.414218 & -1.4142135 & - & -1.4144797 \\
4.0 & - & -1.732052 & -1.7320508 & - & -1.7332924 \\
0.0 & 0.0 & -1.000000 & - & -1.000008 & -1.0000089 \\
1.0 & - & -1.367872 & - & -1.367996 & -1.3679971 \\
2.0 & - & -1.621225 & - & -1.621575 & -1.6215754 \\
4.0 & - & -2.004133 & - & -2.005420 & -2.0054211 \\
\hline
\end{tabular}

The thermal boundary layer becomes thinner. As a continuous stretch in the sheet causes fluid movement in the boundary layer region, the fluid absorbs heat, and a decrease in temperature results. Figure 5 illustrates that the influence of $\beta$, the distance from the origin to the center of magnetic dipole $\alpha_{1}$, and the Curie temperature $\epsilon$ are very important for steadying the ferromagnetic and ferrimagnetic effects on the flow problem. The presence of nano-particles of ferrite in fluid leads to ferromagnetic fluid, the thickness of the fluid intensifies, and a decline, as a result, occurs in the velocity field with increasing values of $\beta$. From Figures 6 and 7, it is clear that increments in the value of $\beta$ causes enhancements in micro-rotation velocity and in temperature dispersals. 


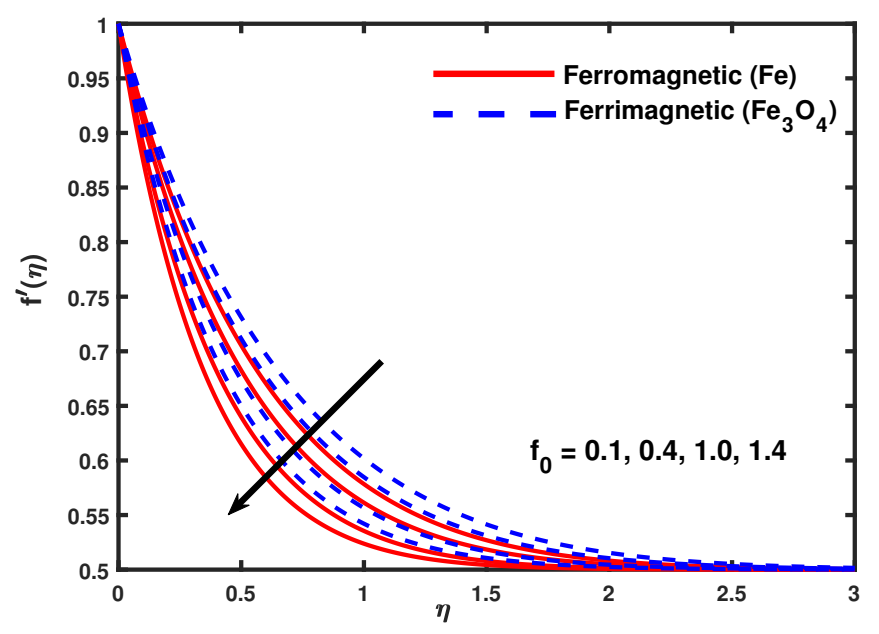

Figure 2. Impact of magnetic nano-particles and suction/injection $\left(f_{0}\right)$ on the velocity profile $f^{\prime}(\eta)$.



Figure 3. Impact of magnetic nano-particles and suction/injection $\left(f_{0}\right)$ on the microrotaion velocity $g(\eta)$.

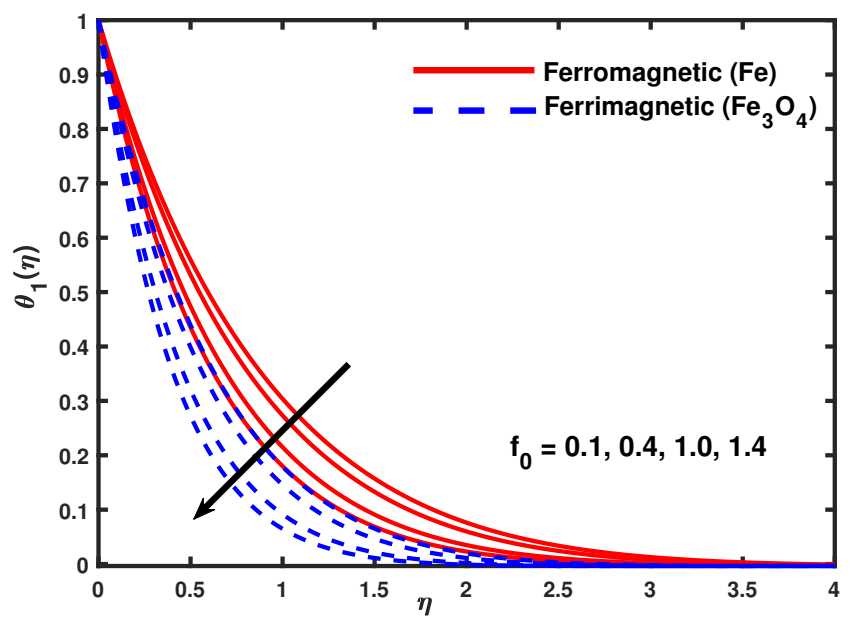

Figure 4. Impact of magnetic nano-particles and suction/injection $\left(f_{0}\right)$ on the temperature profile $\theta_{1}(\eta)$. 


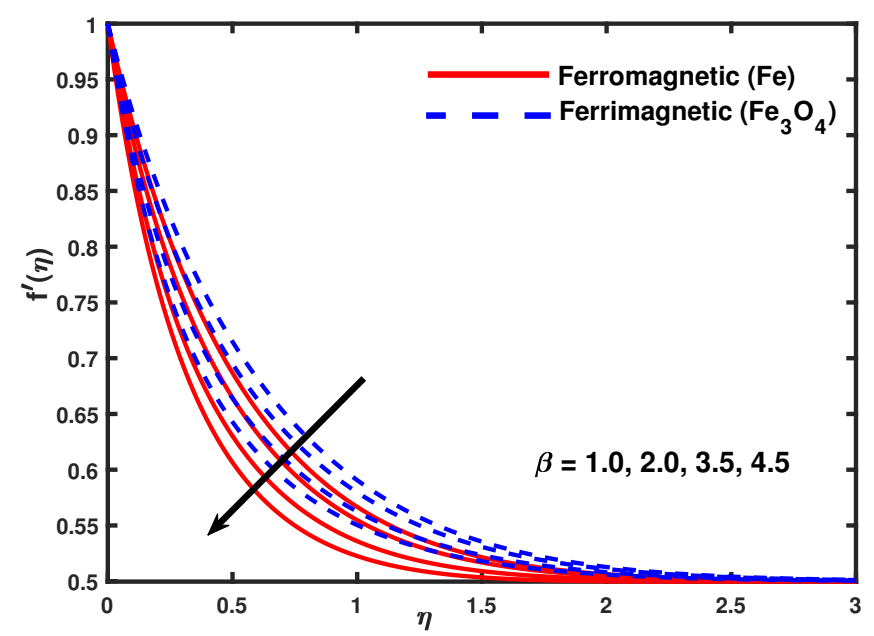

Figure 5. Impact of magnetic nano-particles and ferromagnetic parameter $(\beta)$ on the velocity profile $f^{\prime}(\eta)$.



Figure 6. Impact of magnetic nano-particles and ferromagnetic parameter $(\beta)$ on the micro-rotaion velocity $g(\eta)$.

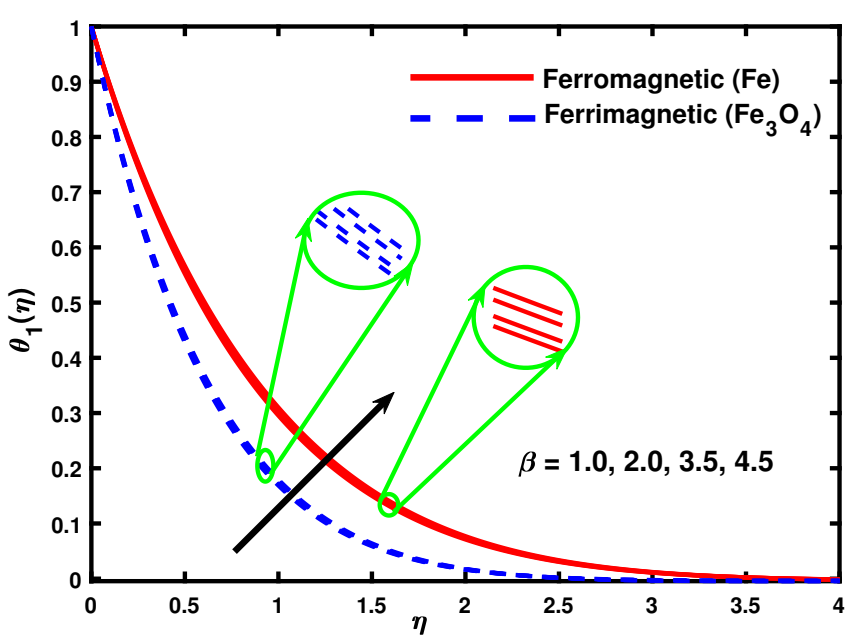

Figure 7. Impact of magnetic nano-particles and ferromagnetic parameter $(\beta)$ on the temperature profile $\theta_{1}(\eta)$. 
Additionally, it was observed that the micro-rotation and thermal boundary layers became thick, but the momentum boundary layer becomes thin. Besides this, the velocity, the micro-rotation velocity, and the temperature have a greater effect on the micro-polar nano-fluid, as it relates to the classical micro-polar fluid. From Figures 8-10 can be perceived as the consequences of $K$ on the velocity, micro-rotation velocity, and temperature by possessing the fixed values of other parameters. With snowballing values of $K$, as shown in Figure 8, the velocity profile increases.



Figure 8. Impact of magnetic nano-particles and micro-rotation parameter $(K)$ on the velocity profile $f^{\prime}(\eta)$.

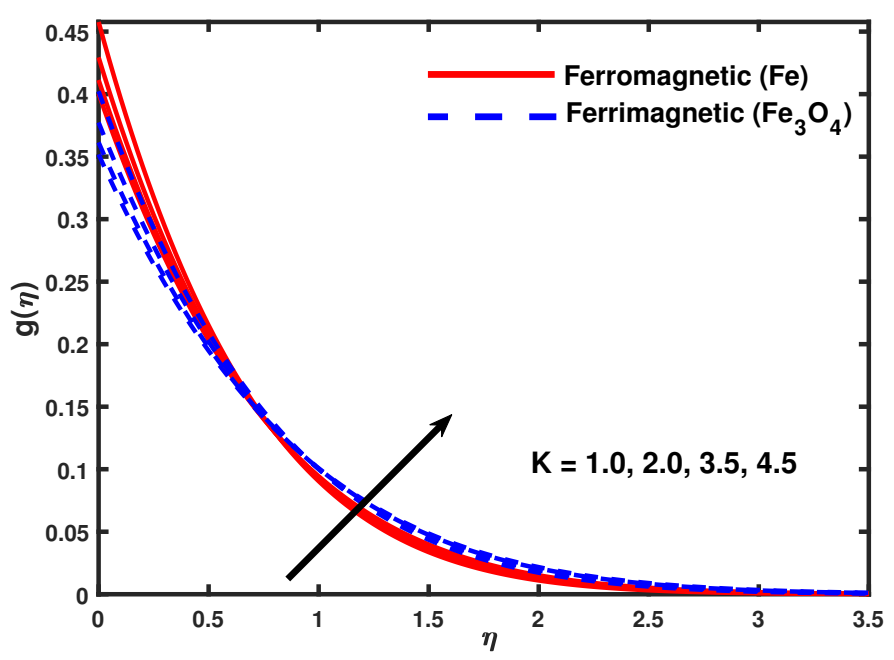

Figure 9. Impact of magnetic nano-particles and micro-rotation parameter $(K)$ on the micro-rotaion velocity $g(\eta)$. 


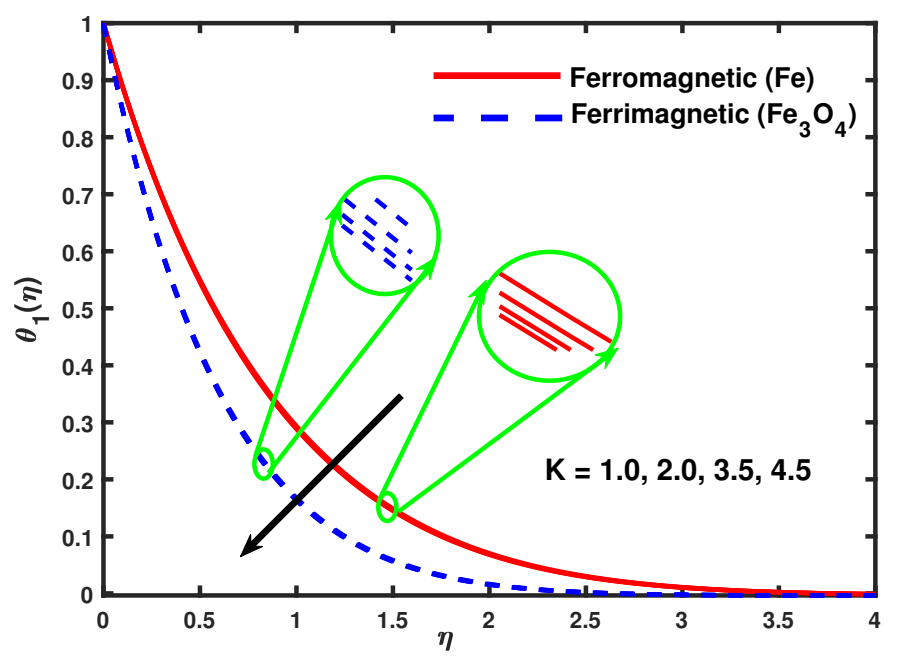

Figure 10. Impact of magnetic nano-particles and micro-rotation parameter $(K)$ on the temperature profile $\theta_{1}(\eta)$.

Figure 9 shows that, when $K$ increases, the micro-rotation velocity becomes smoother and then approaches a free stream value far from the wall, because the antisymmetric portion of the pressure on the boundary that resembles the micro-elements' weak concentration disappears. Figure 10 demonstrates that the thickness of the boundary layer in the temperature field gradually becomes weaker with increasing values of $K$, which shows that the rate of heat transference becomes faster. The generation of a thermal boundary layer will need slightly more time with increasing values of $K$. Figure 11 shows that thermal diffusivity declines as the value of $\mathrm{Pr}$ increases.

The decrease in thermal diffusivity causes heat diffusion in the heated sheet as the surface temperature increases. This reduces the capability of energy that worsens the thermal boundary layer thickness and raises the velocity. In Figure 12, the thermal diffusivity increases as the values of $N$ increases. Figure 13 represents the impact of $R$ (the ratio) on the axial flow velocity. The physiognomies of $R$ are comparatively different for values $R>1$ and $R<1$. Furthermore, the variation in axial velocity for $R=1$ cannot be found, and Figure 14 shows that the micro-rotation velocity decreases with increasing values of $R$.



Figure 11. Impact of magnetic nano-particles and Prandtl Number $(P r)$ on the temperature profile $\theta_{1}(\eta)$. 


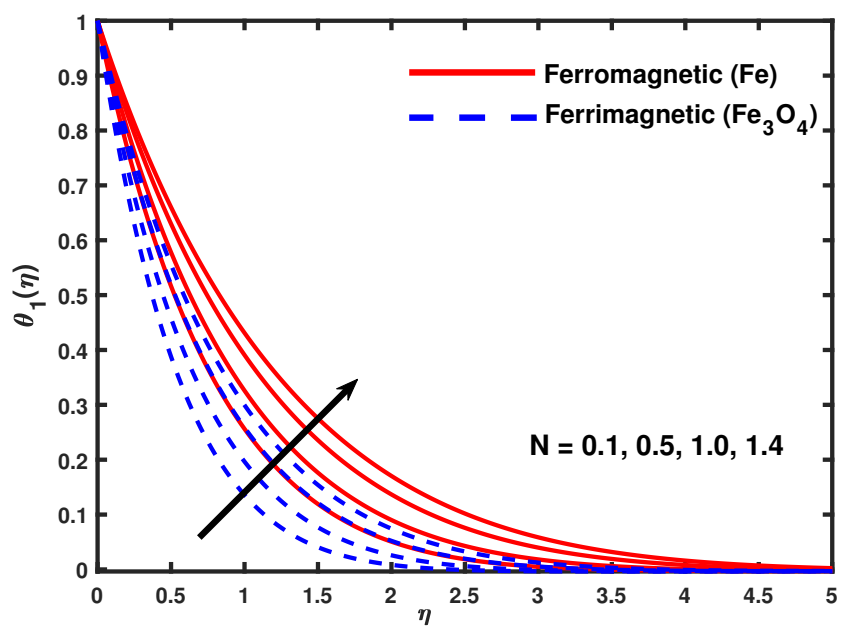

Figure 12. Impact of magnetic nano-particles and thermal radiation $(N)$ on the temperature profile $\theta_{1}(\eta)$.

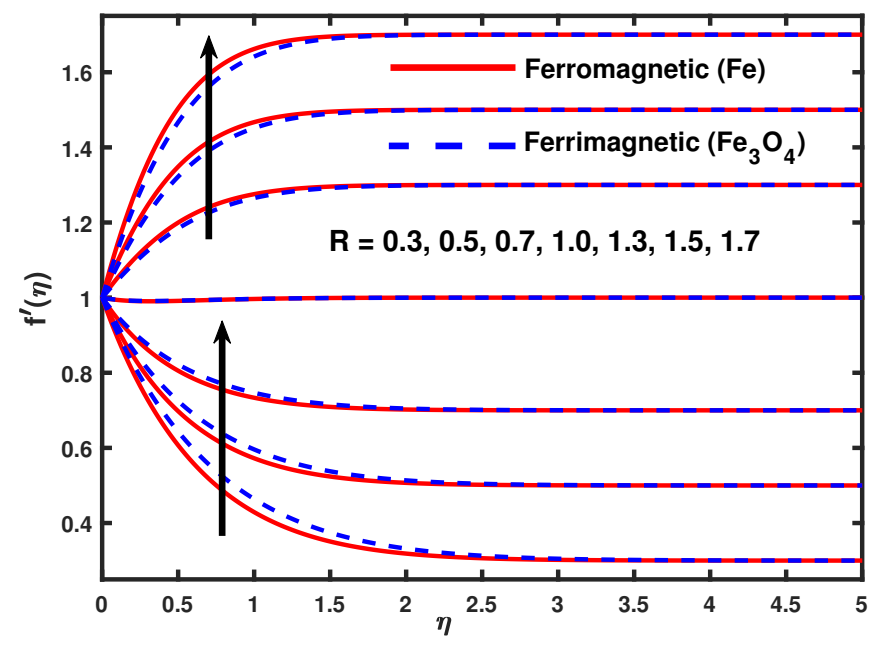

Figure 13. Impact of magnetic nano-particles and $R$ (the ratio of $Q$ and $S$ ) on the velocity profile $f^{\prime}(\eta)$.

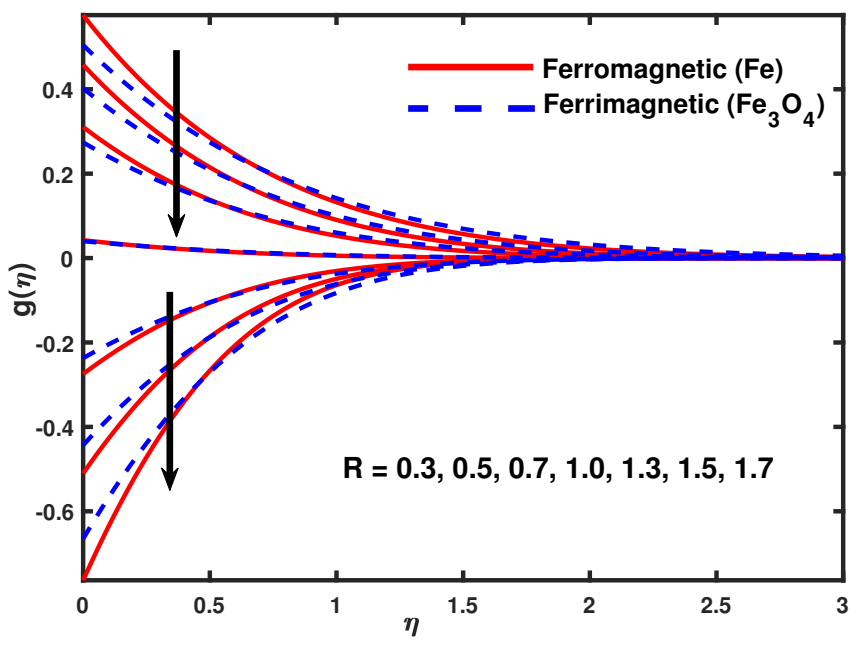

Figure 14. Impact of magnetic nano-particles and $R$ (the ratio of $Q$ and $S$ ) on the micro-rotation velocity $g(\eta)$.

Figure 15 shows the effects of $\lambda$ on temperature. The increment in $\lambda$ increases the heat transfer coefficient, which increases the temperature of the ferromagnetic and ferrimagnetic nano-particles and 
decreases the thermal boundary layer width. The surface temperature is greater for high values of $\lambda$. The discrepancy in heat transfer rates with disparate values of $N, \beta$ and for different nano-particles is shown in Figure 16. The heat transfer rate is higher for growing values of $N$, and the boundary layer thickness is declining. Figure 17 shows that the Nusselt number is high for ferromagnetic nano-particles compared to ferrimagnetic nano-particles.

Additionally, the heat transfer rate increases with increasing values of $\delta$ and $K$. Figure 18 illustrates that the magnitude of the co-efficient of skin friction decreases by increasing values of the parameter $f_{0}$ and $\beta$. Figure 19 shows the skin friction coefficient affected in the presence of a magnetic dipole. The magnetic dipole affects on the $\mathrm{Fe}$ (ferromagnetic) and $\mathrm{Fe}_{3} \mathrm{O}_{4}$ (ferrimagnetic) nano-particles, so the viscosity of the nano-fluid inside the boundary layer is improved, and raises the wall shear stress. Therefore, the coefficient of skin friction increases by increasing values of the parameter $\delta$ and $K$.

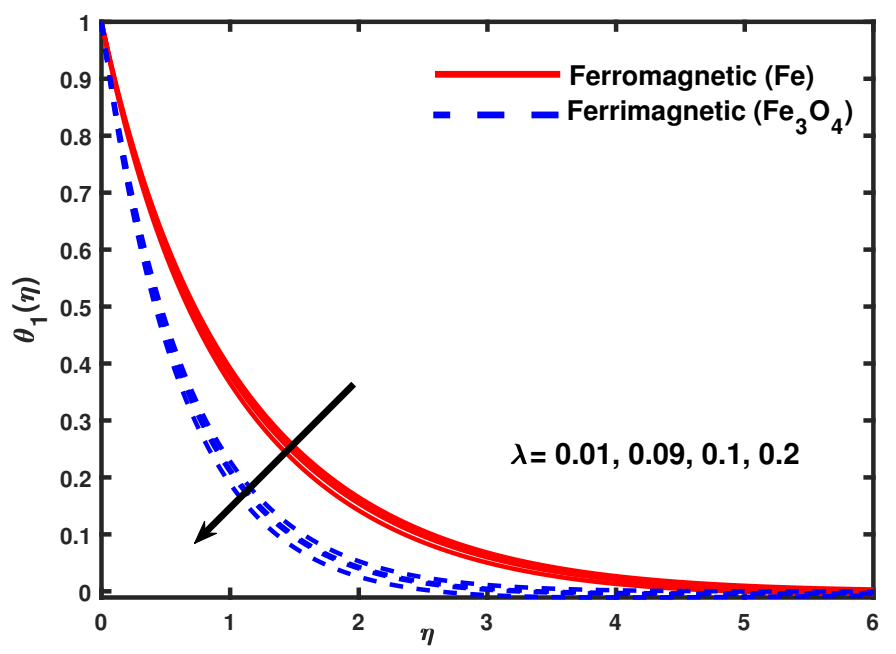

Figure 15. Impact of magnetic nano-particles and viscous dissipation $(\lambda)$ on the temperature profile $\theta_{1}(\eta)$.

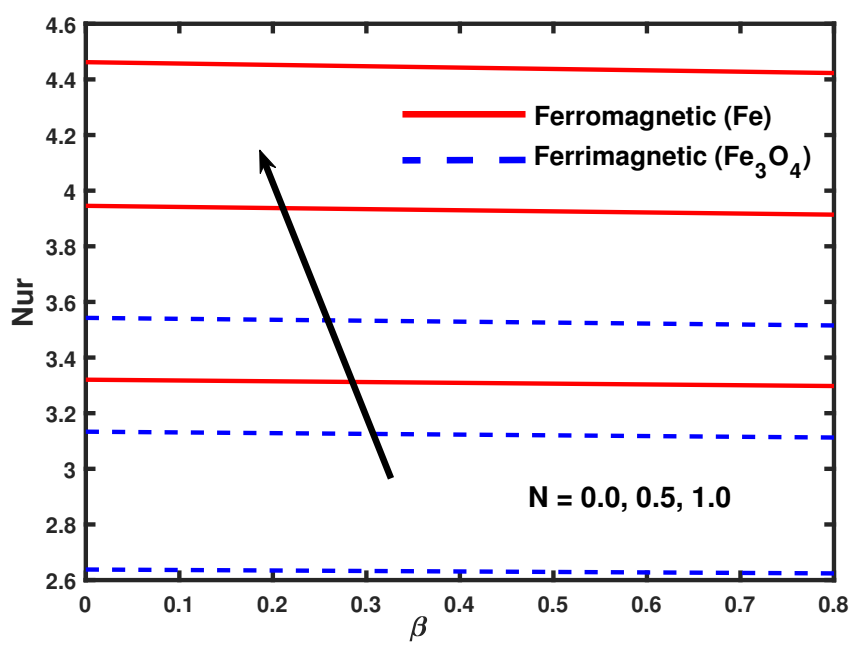

Figure 16. Impact of magnetic nano-particles and thermal radiation $(N)$ on the Nusselt number. 


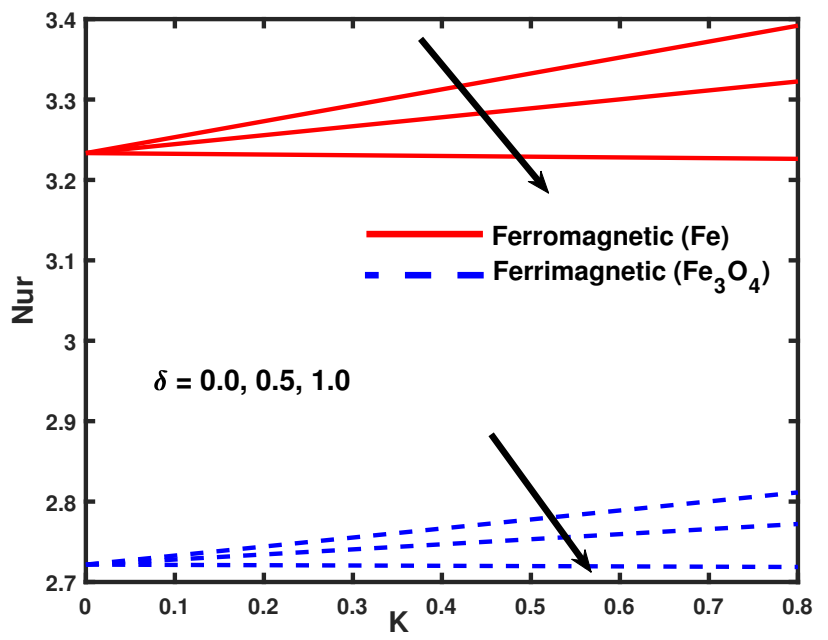

Figure 17. Impact of magnetic nano-particles and boundary parameter $(\delta)$ on the Nusselt number.

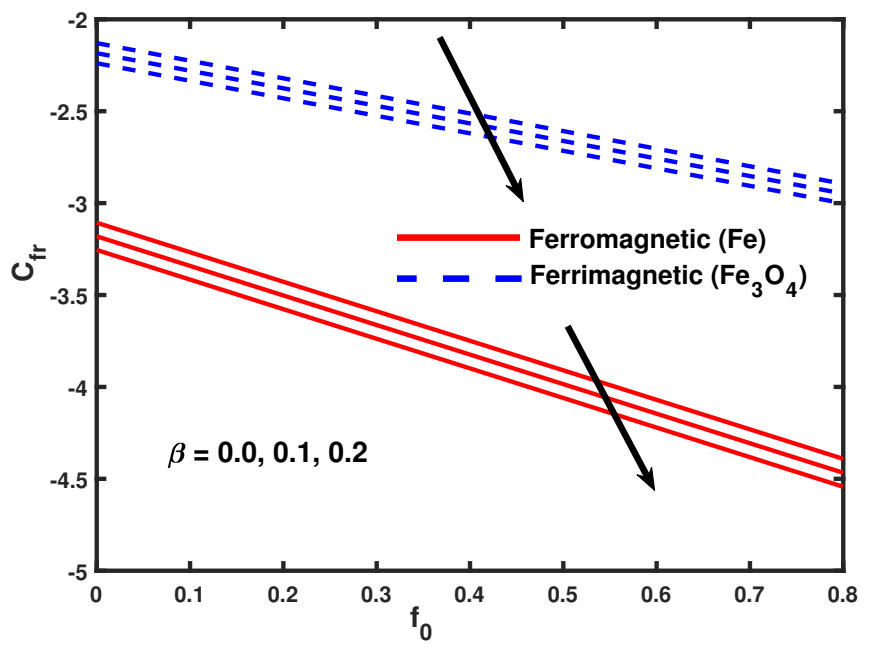

Figure 18. Impact of magnetic nano-particles and ferromagnetic parameter $(\beta)$ on skin friction.

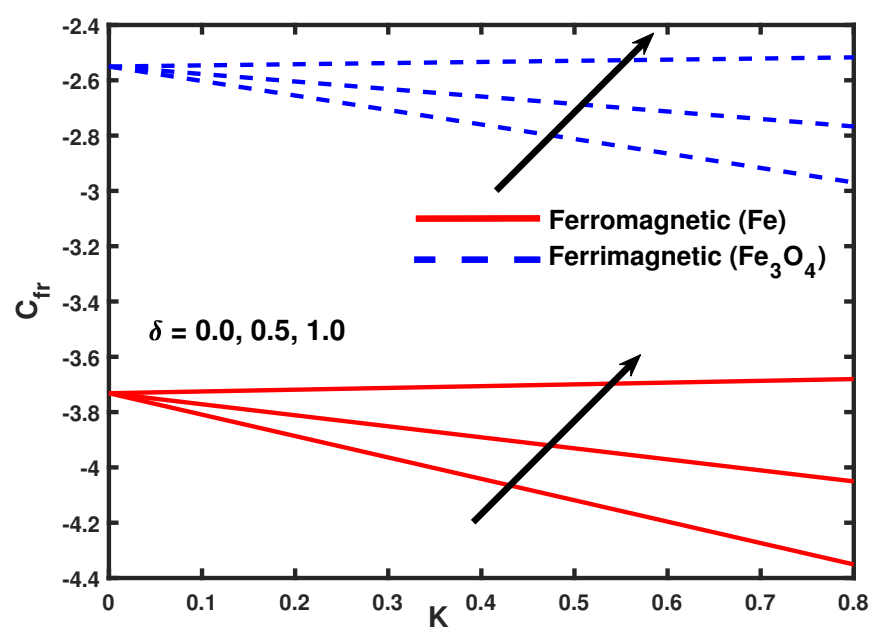

Figure 19. Impact of magnetic nano-particles and boundary parameter $(\delta)$ on skin friction. 


\section{Conclusions}

In the present work, mathematical analysis is performed to explore the behavior of different magnetic nano-particles $\mathrm{Fe}$ and $\mathrm{Fe}_{3} \mathrm{O}_{4}$ on heat transfer and the boundary layer flow of nano-particles, and the the solution of magnetic properties having nano-particles was investigated by applying a magnetic dipole in the micro-polar fluid flow through a stretching sheet. After using the appropriate transformations on the mathematical model to convert the system of equations into ordinary differential equations, the finite element method (FEM) was used to evaluate it. Moreover, a particular case of the existing model is discussed to equate the current results with earlier studies. A parametric study was conducted to explore the effect of different parameters on the velocity, the temperature, the Nusselt number, and the properties of nano-particles. Furthermore, the heat transfer rate, the local skin friction, and the impact of the magnetic dipole on nano-particles were inspected explicitly. Some stirring expositions based on the present study are as follows:

- The velocity profile, the temperature, and the axial velocity are higher in the micro-polar ferromagnetic fluid compared to the ferrimagnetic fluid.

- The velocity profile decreases in the order $\mathrm{Fe}$ (ferromagnetic fluid) and $\mathrm{Fe}_{3} \mathrm{O}_{4}$ (ferrimagnetic fluid).

- Wall shears stress decreases at the variation in the value of parameter $R$ (ratio), and the micro-rotation velocity is increased.

- The consequences of the ferromagnetic parameter generate a reduction in the velocity profile while micro-rotational velocity and temperature are incremented.

- The effects of $K$ on the velocity profile and on the micro-rotational velocity are increasing, but the temperature is declining.

- The Nusselt number is declining for the increasing values of boundary parameter $\delta$, while there is controversy with respect to the increasing values of radiation parameter $N$.

Author Contributions: L.A. and X.L. modeled the problem and wrote the manuscript. X.L. thoroughly checked the mathematical modeling and English. B.A. helped in MATLAB coding. S.M., S.A.K. and S.A. reviewed and edited the paper. X.L. contributed to the results and discussions. All authors have read and agreed to the published version of the manuscript.

Funding: This work was supported by the National Natural Science Foundation of China (No. 51676152), the Equipment Advance Research Field Foundation (No. 61402070302), and the Fundamental Research Funds for the Central Universities (No. zrzd2017012).

Acknowledgments: The first author acknowledges with thanks the Liu Xiaomin for his continuous guidance throughout the work at Xian Jiaotong University, China, as well as the National Natural Science Foundation of China, the Equipment Advance Research Field Foundation, the Fundamental Research Funds for the Central Universities for technical and financial support for this research project. The authors would also like to acknowledge and express their gratitude to the Chinese Government Scholarship Council (CSC) for the scholarship award.

Conflicts of Interest: The authors declare that there is no conflict of interest.

\section{Nomenclature}

$P \quad$ Pressure of fluid

$\alpha_{n f} \quad$ Normal anxiety moduli

$\rho_{n} f \quad$ Fluid density

$\mu_{n f} \quad$ Viscosity of fluid

$H \quad$ Magnetic penetrability

$\mu_{0} \quad$ Magnetic field

$\left(\rho_{c p}\right)_{n f} \quad$ Thermal capability of nano-fluid

$\gamma_{n f} \quad$ Spin gradient viscosity

qr Rosseland eradicative heat flux

$\sigma^{*} \quad$ Stefan-Boltzmann number

$\kappa \quad$ Mean assimilation coefficient 


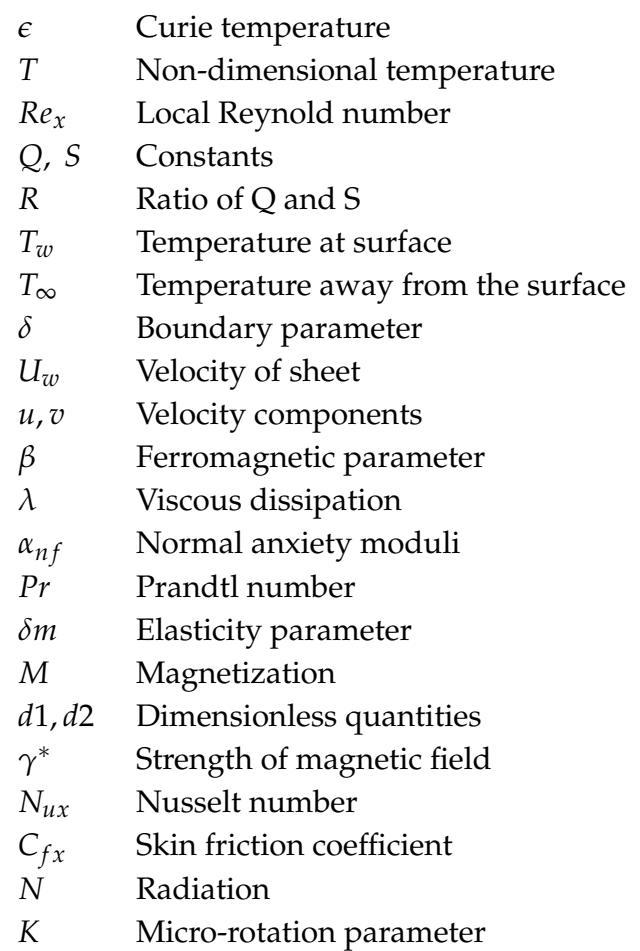

\section{Appendix A}

Appendix A.1. Variational Formulation of FEM

The variational form associated with Equations (24)-(28) over the element $\left(\eta_{b}, \eta_{b+1}\right)$ can be written as

$$
\begin{gathered}
\int_{\eta_{b}}^{\eta_{b+1}} w_{1}\left\{\frac{d f}{d \eta}-h\right\} d \eta=0 \\
\int_{\eta_{b}}^{\eta_{b+1}} w_{2}\left\{\left(A_{5}+K\right) \frac{d^{2} h}{d \eta^{2}}+A_{1} f \frac{d h}{d \eta}-A_{1} h^{2}+K \frac{d g}{d \eta}-\frac{2 \beta \theta_{1}}{(\eta+\gamma)^{4}}+A_{1} R^{2}\right\} d \eta=0 \\
\int_{\eta_{b}}^{\eta_{b+1}} w_{3}\left\{\left(A_{5}+\frac{K}{2}\right) \frac{d^{2} g}{d \eta^{2}}-A_{1} f \frac{d g}{d \eta}+A_{1} g h-K\left(2 g+\frac{d h}{d \eta}\right)\right\} d \eta=0 \\
\int_{\eta_{b}}^{\eta_{b+1}} w_{4}\left\{A_{4}(1+N) \frac{d^{2} \theta_{1}}{d \eta^{2}}+A_{3}\left(f \frac{d \theta_{1}}{d \eta}-2 \theta_{1} h\right)+\frac{2 \lambda \beta f\left(\theta_{1}-\epsilon\right)}{(\eta+\gamma)^{3}}-2 \lambda A_{5} h^{2}\right\} d \eta=0 \\
\int_{\eta_{b}}^{\eta_{b+1}} w_{5}\left\{A_{4}(1+N) \frac{d^{2} \theta_{2}}{d \eta^{2}}+A_{3}\left(f \frac{d \theta_{2}}{d \eta}-4 \theta_{2} h\right)+\frac{2 \lambda \beta \theta_{2}}{(\eta+\gamma)^{3}}\right. \\
\left.-\lambda \beta\left(\theta_{1}-\epsilon\right)\left[2 h /(\eta+\gamma)^{4}+4 f /(\eta+\gamma)^{5}\right]-\lambda A_{5}\left(\frac{d h}{d \eta}\right)^{2}\right\} d \eta=0
\end{gathered}
$$

where $w_{1}, w_{2}, w_{3}, w_{4}$, and $w_{5}$ are the arbitrary test functions and are observed as the variation in $f, h, g$, $\theta_{1}$, and $\theta_{2}$, respectively.

\section{Appendix A.2. Finite Element Formulation}

The finite element model may be obtained for equations by substituting finite element approximations of the form

$$
\bar{f}=\sum_{j=1}^{3} \bar{f}_{j} \psi_{j}, \quad \bar{h}=\sum_{j=1}^{3} \bar{h}_{j} \psi_{j}, \quad \bar{g}=\sum_{j=1}^{3} \bar{g}_{j} \psi_{j}, \quad \bar{\theta}_{1}^{\prime}=\sum_{j=1}^{3} \bar{\theta}_{1 j}^{\prime} \psi_{j}, \quad \bar{\theta}_{2}^{\prime}=\sum_{j=1}^{3} \bar{\theta}_{2 j}^{\prime} \psi_{j}
$$


with $w_{1}=w_{2}=w_{3}=w_{4}=w_{5}=\psi_{i}$, where $i=1,2,3$ and the shape function $\psi_{i}$ for a line element $\Omega_{b}=\left(\eta_{b}, \eta_{b+1}\right)$ are given by

$$
\begin{gathered}
\psi_{1}=\frac{\left(\eta_{b+1}+\eta_{b}-2 \eta\right)\left(\eta_{b+1}-\eta\right)}{\left(\eta_{b+1}-\eta_{b}\right)^{2}}, \quad \psi_{2}=\frac{4\left(\eta-\eta_{b}\right)\left(\eta_{b+1}-\eta\right)}{\left(\eta_{b+1}-\eta_{b}\right)^{2}} \\
\psi_{3}=-\frac{\left(\eta_{b+1}+\eta_{b}-2 \eta\right)\left(\eta-\eta_{b}\right)}{\left(\eta_{b+1}-\eta_{b}\right)^{2}}, \quad \eta_{b} \leq \eta \leq \eta_{b+1}
\end{gathered}
$$

The finite element model of the equations thus formed is given by

$$
\left[\begin{array}{lllll}
H^{11} & H^{12} & H^{13} & H^{14} & H^{15} \\
H^{21} & H^{22} & H^{23} & H^{24} & H^{25} \\
H^{31} & H^{32} & H^{33} & H^{34} & H^{35} \\
H^{41} & H^{42} & H^{43} & H^{44} & H^{45} \\
H^{51} & H^{52} & H^{53} & H^{54} & H^{55}
\end{array}\right]\left[\begin{array}{c}
\{f\} \\
\{h\} \\
\{g\} \\
\left\{\theta_{1}\right\} \\
\left\{\theta_{2}\right\}
\end{array}\right]=\left[\begin{array}{l}
\left\{d_{1}\right\} \\
\left\{d_{2}\right\} \\
\left\{d_{3}\right\} \\
\left\{d_{4}\right\} \\
\left\{d_{5}\right\}
\end{array}\right]
$$

where $H_{m n}$ and $\left\{d_{m}\right\}(m, n=1,2,3,4,5)$ are defined as follows

$$
\begin{aligned}
H_{i j}^{11} & =\int_{\eta_{b}}^{\eta_{b+1}} \psi_{i} \frac{d \psi_{j}}{d \eta} d \eta, \quad H_{i j}^{12}=\int_{\eta_{b}}^{\eta_{b+1}} \psi_{i} \psi_{j} d \eta, \quad H_{i j}^{13}=H_{i j}^{14}=0, H_{i j}^{15}=H_{i j}^{21}=0 . \\
H_{i j}^{22} & =-\left(A_{5}+K\right) \int_{\eta_{b}}^{\eta_{b+1}} \frac{d \psi_{i}}{d \eta} \frac{d \psi_{j}}{d \eta} d \eta+A_{1} \int_{\eta_{b}}^{\eta_{b+1}} \bar{f} \psi_{i} \frac{d \psi_{j}}{d \eta} d \eta-A_{1} \int_{\eta_{b}}^{\eta_{b+1}} \bar{h} \psi_{i} \psi_{j} d \eta, \quad H_{i j}^{23}=K \int_{\eta_{b}}^{\eta_{b+1}} \psi_{i} \frac{d \psi_{j}}{d \eta} d \eta, \\
H_{i j}^{24} & =\frac{-2 \beta}{(\eta+\gamma)^{4}} \int_{\eta_{b}}^{\eta_{b+1}} \psi_{i} \psi_{j} d \eta, \quad H_{i j}^{25}=0, \quad H_{i j}^{31}=0, \quad H_{i j}^{32}=-K \int_{\eta_{b}}^{\eta_{b+1}} \psi_{i} \frac{d \psi_{j}}{d \eta} d \eta, \\
H_{i j}^{33} & =-\left(A_{5}+\frac{K}{2}\right) \int_{\eta_{b}}^{\eta_{b+1}} \frac{d \psi_{i}}{d \eta} \frac{d \psi_{j}}{d \eta} d \eta-A_{1} \int_{\eta_{b}}^{\eta_{b+1}} \bar{f} \psi_{i} \frac{d \psi_{j}}{d \eta} d \eta d \eta+A_{1} \int_{\eta_{b}}^{\eta_{b+1}} \bar{h} \psi_{i} \psi_{j} \\
& -2 K \int_{\eta_{b}}^{\eta_{b+1}} \psi_{i} \psi_{j} d \eta, \quad H_{i j}^{33}=H_{i j}^{35}=0, \quad H_{i j}^{41}=\frac{-2 \beta \lambda \epsilon}{(\eta+\gamma)^{3}} \int_{\eta_{b}}^{\eta_{b+1}} \psi_{i} \psi_{j} d \eta, \\
H_{i j}^{42} & =-2 A_{5} \lambda \int_{\eta_{b}}^{\eta_{b+1}} \bar{h} \psi_{i} \psi_{j} d \eta, \quad H_{i j}^{43}=0, \quad H_{i j}^{45}=0, \quad H_{i j}^{44}=-A_{4}(1+N) \int_{\eta_{b}}^{\eta_{b+1}} \frac{d \psi_{i}}{d \eta} \frac{d \psi_{j}}{d \eta} d \eta \\
& +A_{3} \int_{\eta_{b}}^{\eta_{b+1}} \bar{f} \psi_{i} \frac{d \psi_{j}}{d \eta} d \eta-2 A_{3} \int_{\eta_{b}}^{\eta_{b+1}} \bar{h} \psi_{i} \psi_{j} d \eta+\frac{-2 \beta \lambda}{(\eta+\gamma)^{3}} \int_{\eta_{b}}^{\eta_{b+1}} \bar{f} \psi_{i} \psi_{j} d \eta, \quad H_{i j}^{51}=-\frac{4 \beta \lambda}{(\eta+\gamma)^{5}} \int_{\eta_{b}}^{\eta_{b+1}} \psi_{i} \psi_{j} d \eta, \\
H_{i j}^{52} & =\frac{2 \beta \lambda \epsilon}{(\eta+\gamma)^{4}} \int_{\eta_{b}}^{\eta_{b+1}} \psi_{i} \psi_{j} d \eta-\lambda A_{5} \int_{\eta_{b}}^{\eta_{b+1}} \bar{h}^{\prime} \psi_{i} \frac{d \psi_{j}}{d \eta} d \eta, \quad H_{i j}^{53}=0 \quad H_{i j}^{54}=\frac{-2 \beta \lambda}{(\eta+\gamma)^{4}} \int_{\eta_{b}}^{\eta_{b+1}} \bar{h} \psi_{i} \psi_{j} d \eta \\
& -\frac{4 \beta \lambda}{(\eta+\gamma)^{5}} \int_{\eta_{b}}^{\eta_{b+1}} \bar{f} \psi_{i} \psi_{j} d \eta . \quad H_{i j}^{55}=-A_{4}(1+N) \int_{\eta_{b}}^{\eta_{b+1}} \frac{d \psi_{i}}{d \eta} \frac{d \psi_{j}}{d \eta} d \eta \\
& +A_{3} \int_{\eta_{b}}^{\eta_{b+1}} \bar{f} \psi_{i} \frac{d \psi_{j}}{d \eta} d \eta-4 A_{3} \int_{\eta_{b}}^{\eta_{b+1}} \bar{h} \psi_{i} \psi_{j} d \eta+\frac{2 \beta \lambda}{(\eta+\gamma)^{3}} \int_{\eta_{b}}^{\eta_{b+1}} \psi_{i} \psi_{j} d \eta
\end{aligned}
$$

and

$$
\begin{aligned}
& d_{i}^{1}=0, \quad d_{i}^{2}=-A_{1} R^{2} \int_{\eta_{b}}^{\eta_{b+1}} \psi_{i} d \eta-\left(A_{5}+K\right)\left(\psi \frac{d h}{d \eta}\right)_{\eta_{b}}^{\eta_{b}+1}, \quad d_{i}^{3}=-\left(A_{5}+\frac{K}{2}\right)\left(\psi \frac{d g}{d \eta}\right)_{\eta_{b}}^{\eta_{b}+1}, \\
& d_{i}^{4}=-A_{4}(1+N)\left(\psi \frac{d \theta_{1}}{d \eta}\right)_{\eta_{b}}^{\eta_{b}+1}, \quad d_{i}^{5}=-A_{4}(1+N)\left(\psi \frac{d \theta_{1}}{d \eta}\right)_{\eta_{b}}^{\eta_{b}+1}
\end{aligned}
$$

where $\quad \bar{f}=\sum_{j=1}^{3} \bar{f}_{j} \psi_{j}, \quad \bar{h}=\sum_{j=1}^{3} \bar{h}_{j} \psi_{j}, \quad \bar{g}=\sum_{j=1}^{3} \bar{g}_{j} \psi_{j}, \quad \bar{\theta}_{1}^{\prime}=\sum_{j=1}^{3} \bar{\theta}_{1 j}^{\prime} \psi_{j}$, and $\quad \bar{\theta}_{2}^{\prime}=\sum_{j=1}^{3} \bar{\theta}_{2 j}^{\prime} \psi_{j}$, are considered unknown. 


\section{References}

1. Das, S.K.; Choi, S.U.; Yu, W.; Pradeep, T. Nanofluids: Science and Technology; John Wiley \& Sons: Hoboken, NJ, USA, 2007.

2. Keblinski, P.; Prasher, R.; Eapen, J. Thermal conductance of nanofluids: Is the controversy over? J. Nanoparticle Res. 2008, 10, 1089-1097. [CrossRef]

3. Godson, L.; Raja, B.; Lal, D.M.; Wongwises, S. Enhancement of heat transfer using nanofluids-An overview. Renew. Sustain. Energy Rev. 2010, 14, 629-641. [CrossRef]

4. Özerinç, S.; Kakaç, S.; Yazıcıoğlu, A.G. Enhanced thermal conductivity of nanofluids: A state-of-the-art review. Microfluid. Nanofluid. 2010, 8, 145-170. [CrossRef]

5. Wen, D.; Lin, G.; Vafaei, S.; Zhang, K. Review of nanofluids for heat transfer applications. Particuology 2009, 7, 141-150. [CrossRef]

6. Sakiadis, B. Boundary-layer behavior on continuous solid surfaces: II. The boundary layer on a continuous flat surface. AiChE J. 1961, 7, 221-225. [CrossRef]

7. Crane, L.J. Flow past a stretching plate. Z. Angew. Math. Phys. 1970, 21, 645-647. [CrossRef]

8. Mee, C. The mechanism of colloid agglomeration in the formation of Bitter patterns. Proc. Phys. Soci. Sect. A 1950, 63, 922. [CrossRef]

9. Neuringer, J.L. Some viscous flows of a saturated ferro-fluid under the combined influence of thermal and magnetic field gradients. Int. J. Non-Linear Mech. 1966, 1, 123-137. [CrossRef]

10. Nadeem, S.; Raishad, I.; Muhammad, N.; Mustafa, M. Mathematical analysis of ferromagnetic fluid embedded in a porous medium. Results Phys. 2017, 7, 2361-2368. [CrossRef]

11. Andersson, H.; Valnes, O. Flow of a heated ferrofluid over a stretching sheet in the presence of a magnetic dipole. Acta Mech. 1998, 128, 39-47. [CrossRef]

12. Bognár, G.; Hriczó, K. Ferrofluid flow in the presence of magnetic dipole. Tech. Mech. 2019, 39, 3-15.

13. Tang, T.; Fu, Y. Formation of chitosan/sodium phytate/nano- $\mathrm{Fe}_{3} \mathrm{O}_{4}$ magnetic coatings on wood surfaces via layer-by-layer self-assembly. Coatings 2020, 10, 51. [CrossRef]

14. Ali, L.; Liu, X.; Ali, B.; Mujeed, S.; Abdal, S. Finite element simulation of multi-slip effects on unsteady MHD bioconvective micropolar nanofluid flow over a sheet with solutal and thermal convective boundary conditions. Coatings 2019, 9, 842. [CrossRef]

15. Mabood, F.; Khan, W.; Ismail, A.M. MHD boundary layer flow and heat transfer of nanofluids over a nonlinear stretching sheet: A numerical study. J. Magn. Magn. Mater. 2015, 374, 569-576. [CrossRef]

16. Ganguly, R.; Puri, I.K. Field-assisted self-assembly of superparamagnetic nanoparticles for biomedical, MEMS and BioMEMS applications. Adv. Appl. Mech. 2007, 41, 293-335.

17. Odenbach, S. Recent progress in magnetic fluid research. J. Phys. Condens. Matter 2004, 16, R1135. [CrossRef]

18. Nkurikiyimfura, I.; Wang, Y.; Pan, Z. Heat transfer enhancement by magnetic nanofluids-A review. Renew. Sustain. Energy Rev. 2013, 21, 548-561. [CrossRef]

19. Turkyilmazoglu, M. Flow of a micropolar fluid due to a porous stretching sheet and heat transfer. Int. J. Non-Linear Mech. 2016, 83, 59-64. [CrossRef]

20. Pradhan, S.; Baag, S.; Mishra, S.; Acharya, M. Free convective MHD micropolar fluid flow with thermal radiation and radiation absorption: A numerical study. Heat Transf. Res. 2019, 48, 2613-2628. [CrossRef]

21. Ishak, A.; Lok, Y.Y.; Pop, I. Stagnation-point flow over a shrinking sheet in a micropolar fluid. Chem. Eng. Commun. 2010, 197, 1417-1427. [CrossRef]

22. Eringen, A.C. Theory of micropolar fluids. J. Math. Mech. 1966, 16, 1-18. [CrossRef]

23. Gorla, R.S.R. Micropolar boundary layer flow at a stagnation point on a moving wall. Int. J. Eng. Sci. 1983, 21, 25-33. [CrossRef]

24. Li, Q.; Xuan, Y.; Wang, J. Experimental investigations on transport properties of magnetic fluids. Exp. Therm. Fluid Sci. 2005, 30, 109-116. [CrossRef]

25. Yirga, Y.; Tesfay, D. Heat and mass transfer in MHD flow of nanofluids through a porous media due to a permeable stretching sheet with viscous dissipation and chemical reaction effects. Int. J. Mech. Aero. Indus Mecha manu Eng. 2015, 9, 674-681.

26. Nadeem, S.; Muhammad, N. Impact of stratification and Cattaneo-Christov heat flux in the flow saturated with porous medium. J. Mol. Liq. 2016, 224, 423-430. [CrossRef] 
27. Muhammad, N.; Nadeem, S.; Haq, R.U. Heat transport phenomenon in the ferromagnetic fluid over a stretching sheet with thermal stratification. Results Phys. 2017, 7, 854-861. [CrossRef]

28. Ibrahim, W.; Shankar, B. MHD boundary layer flow and heat transfer of a nanofluid past a permeable stretching sheet with velocity, thermal and solutal slip boundary conditions. Comput. Fluids 2013, 75, 1-10. [CrossRef]

29. Das, K. Slip flow and convective heat transfer of nanofluids over a permeable stretching surface. Comput. Fluids 2012, 64, 34-42. [CrossRef]

30. Abbas, Z.; Wang, Y.; Hayat, T.; Oberlack, M. Slip effects and heat transfer analysis in a viscous fluid over an oscillatory stretching surface. Int. J. Numer. Methods Fluids 2009, 59, 443-458. [CrossRef]

31. Titus, L.; Abraham, A. Ferromagnetic liquid flow due to gravity-aligned stretching of an elastic sheet. J. Appl. Fluid Mech. 2015, 8, 591-600. [CrossRef]

32. Tiwari, R.K.; Das, M.K. Heat transfer augmentation in a two-sided lid-driven differentially heated square cavity utilizing nanofluids. Int. J. Heat Mass Transf. 2007, 50, 2002-2018. [CrossRef]

33. Palaniappan, B.; Ramasamy, V. Thermodynamic analysis of fly ash nanofluid for automobile (heavy vehicle) radiators. J. Therm. Anal. Calorim. 2019, 136, 223-233. [CrossRef]

34. Domkundwar, A.; Domkundwar, V. Heat and Mass Transfer Data Book; Dhanpat Rai: Hisar, India, 2007.

35. Reddy, J.N. An Introduction to the Finite Element Method; McGraw-Hill Education: New York, NY, USA, 1993.

36. Swapna, G.; Kumar, L.; Rana, P.; Singh, B. Finite element modeling of a double-diffusive mixed convection flow of a chemically-reacting magneto-micropolar fluid with convective boundary condition. J. Taiwan Inst. Chem. Eng. 2015, 47, 18-27. [CrossRef]

37. Gupta, D.; Kumar, L.; Beg, O.A.; Singh, B. Finite element analysis of transient heat and mass transfer in mircostructural boundary layer flow from a porous stretching sheet. Comput. Therm. Sci. Int. J. 2014, 6, 155-169. [CrossRef]

38. Ali, L.; Liu, X.; Ali, B.; Mujeed, S.; Abdal, S. Finite element analysis of thermo-diffusion and multi-slip effects on MHD unsteady flow of casson nano-fluid over a shrinking/stretching sheet with radiation and heat source. Appl. Sci. 2019, 9, 5217. [CrossRef]

39. Ali, B.; Nie, Y.; Khan, S.A.; Sadiq, M.T.; Tariq, M. Finite element simulation of multiple slip effects on MHD unsteady maxwell nanofluid flow over a permeable stretching sheet with radiation and thermo-diffusion in the presence of chemical reaction. Processes 2019, 7, 628. [CrossRef]

40. Majeed, A.; Zeeshan, A.; Ellahi, R. Unsteady ferromagnetic liquid flow and heat transfer analysis over a stretching sheet with the effect of dipole and prescribed heat flux. J. Mol. Liq. 2016, 223, 528-533. [CrossRef]

41. Bachok, N.; Ishak, A.; Nazar, R. Flow and heat transfer over an unsteady stretching sheet in a micropolar fluid. Meccanica 2011, 46, 935-942. [CrossRef]

42. Qasim, M.; Khan, I.; Shafie, S. Heat transfer in a micropolar fluid over a stretching sheet with Newtonian heating. PLoS ONE 2013, 8, e59393. [CrossRef]

43. Hussanan, A.; Salleh, M.Z.; Khan, I. Microstructure and inertial characteristics of a magnetite ferrofluid over a stretching/shrinking sheet using effective thermal conductivity model. J. Mol. Liq. 2018, 255, 64-75. [CrossRef]

44. Kumar, L. Finite element analysis of combined heat and mass transfer in hydromagnetic micropolar flow along a stretching sheet. Comput. Mater. Sci. 2009, 46, 841-848. [CrossRef]

(C) 2020 by the authors. Licensee MDPI, Basel, Switzerland. This article is an open access article distributed under the terms and conditions of the Creative Commons Attribution (CC BY) license (http://creativecommons.org/licenses/by/4.0/). 